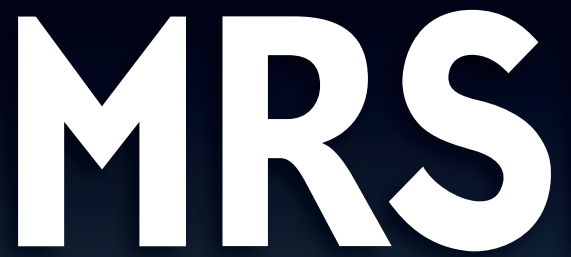

$\mathrm{M}|\mathrm{R}| \mathrm{S}$
MATERIALS RESEARCH SOCIETY ${ }^{\circledR}$

Advancing materials. Improving the quality of life.

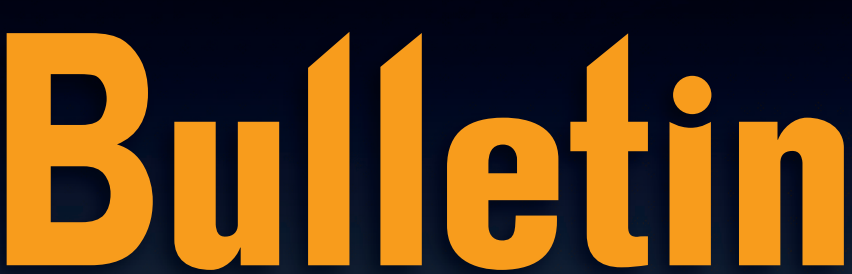

February 2020 Vol. 45 No. 2 mrs.org/bulletin

\title{
Transient electronic devices
}

\section{ALSO IN THIS ISSUE}

Self-assembly of functional nanoscale materials

\section{chescale materals}




\section{PARTICLE ACCELERATOR SYSTEMS}

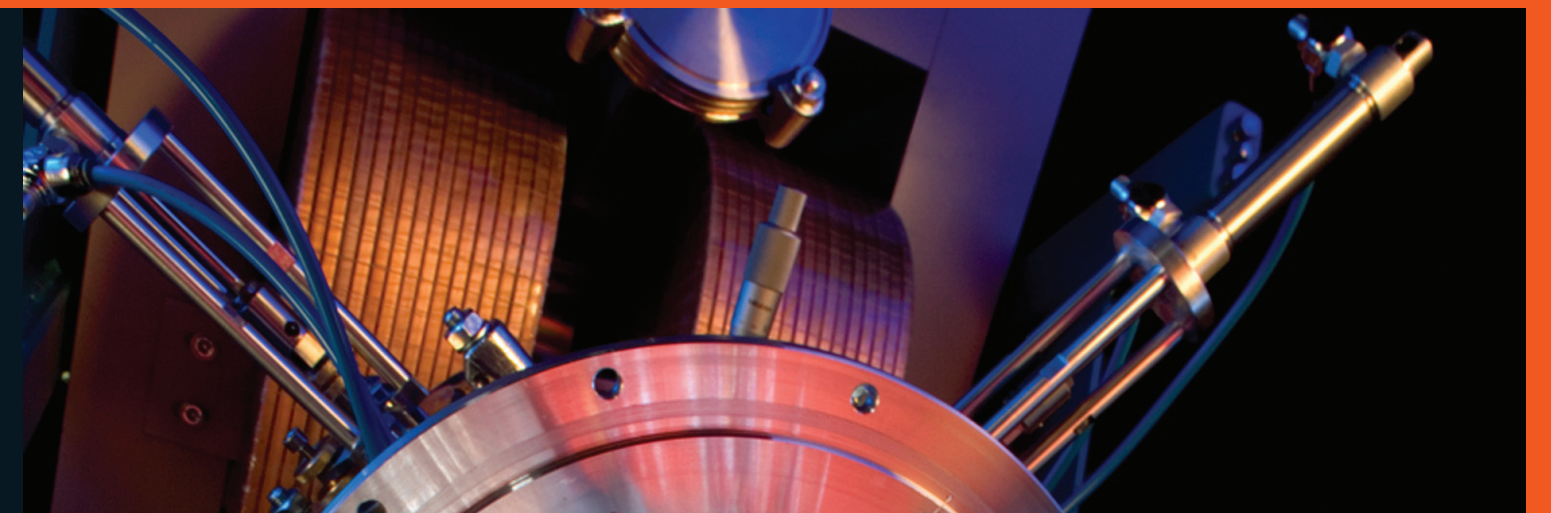

口 Ion Accelerator Systems

- Ion Implanters

- Systems for lon Beam Analysis

- Accelerator Mass Spectrometers

- Systems for $\boldsymbol{\mu}$-beam Applications

- Neutron Generator Systems

Electron Accelerator Systems

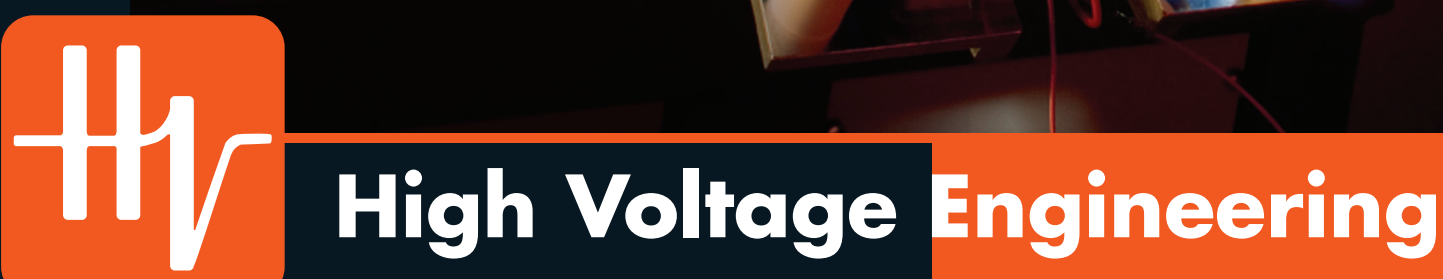

High Voltage Engineering Europa B.V.

P.O. Box 99, 3800 AB Amersfoort, The Netherlands Tel: 31334619741 • info@highvolteng.com 


\section{REGISTER BY MARCH 27 AND SAVE!}

\section{Spring Meeting registrations include MRS Membership July 1, 2020 - June 30, 2021}

\section{CHARACTERIZATION AND THEORY}

CT01 Artificial Intelligence for Material Design, Processing and Characterizations

CT02 Halide Perovskites-

From Lead-Free Materials to Advanced Characterization and Deposition Approaches

CT03 Expanding the Frontiers of Actinide Materials Science

Through Experiment and Theory

CT04 Tailored Interphases for High Strength and Functional Composites-

Advances in Experiments, Simulations and Al-Based Design

СT05 Defects, Order and Disorder in Structural and Functional Fluorite-Related Compounds

CT06 Local and Global Fluctuations in Plasticity

CT07 Micro-Assembly Technologies and Heterogeneous IntegrationFundamentals to Applications

CT08 Crystallization via Nonclassical Pathways in Synthetic, Biogenic and Geologic Environments

\section{ELECTRONICS AND PHOTONICS}

EL01 Surfaces and Interfaces in Electronics and Photonics

EL02 Advanced Manufacturing of Mixed Dimensional Heterostructures

EL03 Novel Approaches and Material Platforms for Enhanced Light-Matter Interaction, Plasmonics and Metasurfaces

EL04 Materials for Nonlinear and Nonreciprocal Photonics

EL05 Scalable Photonic Material Platforms-Applications and Manufacturing Advances

EL06 Photonic Materials for Information Processing and Computing

EL07 Fundamental Mechanisms and Materials Discovery for Brain-Inspired Computing Theory and Experiment

EL08 Neuromorphic Materials and Devices for Bioinspired Computing and Artificial Intelligence

EL09 Phase-Change Materials for Electronic and Photonic Nonvolatile Memory and Neuro-Inspired Computing

EL10 Electroactive Ceramics for Information Technologies and Flexible Electronics

EL11 Lead-Free Ferroelectrics and Their Emerging Applications

EL12 Ferroic Materials and Heterostructures for Electronics and Data Storage

EL13 Processing, Microstructure and Multifunctioning of Organic Semiconductors

EL14 New Materials Design for Organic Semiconductors Through Multimodel Characterization and Computational Techniques

EL15 Ultra-Wide Bandgap Materials, Devices and Systems

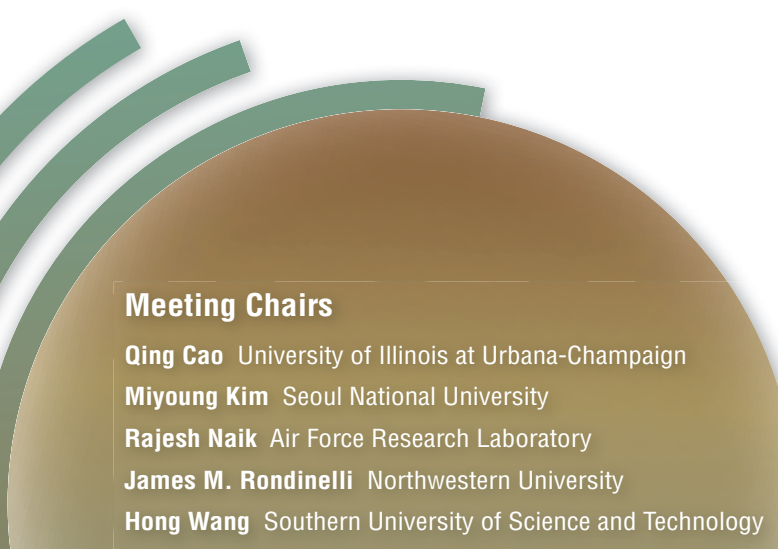

\section{Don't Miss These Future MRS Meetings!}

2020 MRS Fall Meeting \& Exhibit

November 29-December 4, 2020, Boston, Massachusetts

\author{
ENERGY, STORAGE AND CONVERSION \\ EN01 Next Steps for Perovskite Photovoltaics and Beyond \\ EN02 Caloric Materials for Sustainable Cooling Applications \\ EN03 Solar-Energy Conversion for Sustainable Water-Energy-Environmental Nexus \\ EN04 Dual-Ion Batteries as an Emerging Technology for Sustainable Energy Storage- \\ Anion Storage Materials and Full Dual-Ion Battery Devices \\ EN05 Low-Cost Aqueous Rechargeable Battery Technologies \\ EN06 Rational Designed Hierarchical Nanostructures for Photocatalytic System \\ EN07 Next-Generation Electrical Energy Storage-Beyond Intercalation-Type Lithium Ion \\ EN08 Multivalent-Based Electrochemical Energy Storage \\ EN09 Flow-Based Open Electrochemical Systems \\ EN10 Emerging Inorganic Semiconductors for Solar-Energy Conversion \\ EN11 Materials, Modeling and Technoeconomic Impacts for Large-Scale \\ Hydrogen and Energy Applications \\ EN12 Materials for Safe and Sustainable Electrochemical Energy Storage
}

\section{NANOSCALE AND QUANTUIM MIATERIALS}

NM01 Nanodiamonds-Synthesis, Properties and Applications

NM02 Colloidal Nanoparticles-From Synthesis to Applications

NM03 Nanomanipulation of Materials

NM04 Nanosafety

NM05 1D Carbon Electronics-From Synthesis to Applications

NM06 Theory and Characterization of 2D Materials-

Bridging Atomic Structure and Device Performance

NM07 Two-Dimensional Quantum Materials Out of Equilibrium

NM08 2D Atomic and Molecular Sheets-

Electronic and Photonic Properties and Device Applications

NM09 Layered van der Waals Heterostructures-

Synthesis, Physical Phenomena and Devices

NM10 Synthesis, Properties and Applications of 2D MXenes

NM11 Topological and Quantum Phenomena in Oxides and Oxide Heterostructures

NM12 Synthesis and Control of Dirac or Topological Materials

\section{SOFT MIATERIALS AND BIOMIATERIALS}

SM01 Organ-on-a-Chip-Toward Personalized Precision Medicine

SM02 Progress in Open-Space Microfluidics-

From Nanoscience, Manufacturing to Biomedicine

SM03 Flexible, Stretchable Biointegrated Materials, Devices and Related Mechanics

SM04 Fundamental Materials, Devices and Fabrication Innovations for Biointegrated and Bioinspired Electronics

SM05 Engineered Functional Multicellular Circuits, Devices and Systems

SM06 Soft Organic and Hybrid Materials for BiointerfacingMaterials, Processes and Applications

SM07 Bioinspired Synthesis and Manufacturing of Materials

SM08 Emerging Strategies and Applications in Drug Delivery

SM09 Advances in 3D Printing for Medical Applications

\section{FOLLOW THE MEETING!}

\#S2OMRS 0 ( 9

MR S MATERIALS RESEARCH SOCIETY ${ }^{\circledR}$ Advancing materials. Improving the quality of life.

\section{mrs.org/spring2020}

Updated information as of 6/28/19 

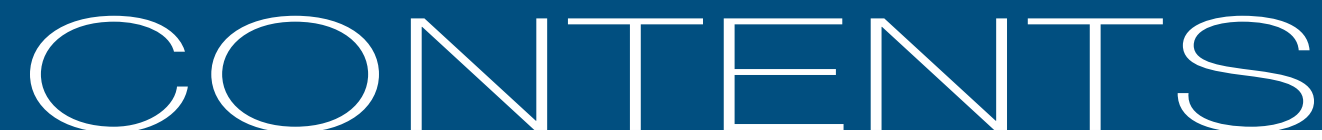

\section{TRANSIENT ELECTRONIC DEVICES}

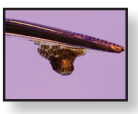

87 The emergence of transient

electronic devices

Seung-Kyun Kang, Lan Yin,

and Christopher Bettinger, Guest Editors

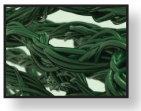

96 Biodegradable and stretchable polymeric materials for transient electronic devices Kathy Liu, Helen Tran, Vivian Rachel Feig, and Zhenan Bao

103 Inorganic materials for transient electronics in biomedical applications

Yeonsik Choi, Jahyun Koo, and John A. Rogers

113 Advanced manufacturing for transient electronics

Won Bae Han, Gwan-Jin Ko, Jeong-Woong Shin, and Suk-Won Hwang

121 Energy materials for transient power sources Xiaoteng Jia, Caiyun Wang, Chong-Yong Lee, Changchun Yu, and Gordon G. Wallace

129 Material strategies for on-demand smart transient electronics

Chunyu You, Haonan Zhao, Qinglei Guo, and Yongfeng Mei

\section{TECHNICAL FEATURE}

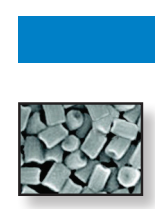

135 Self-assembly of functional nanoscale materials

\section{MRS Mid-Career Researcher Award presentation}

Feng Bai, Kaifu Bian, Binsong Li, Casey Karler, Ashley Bowman, and Hongyou Fan
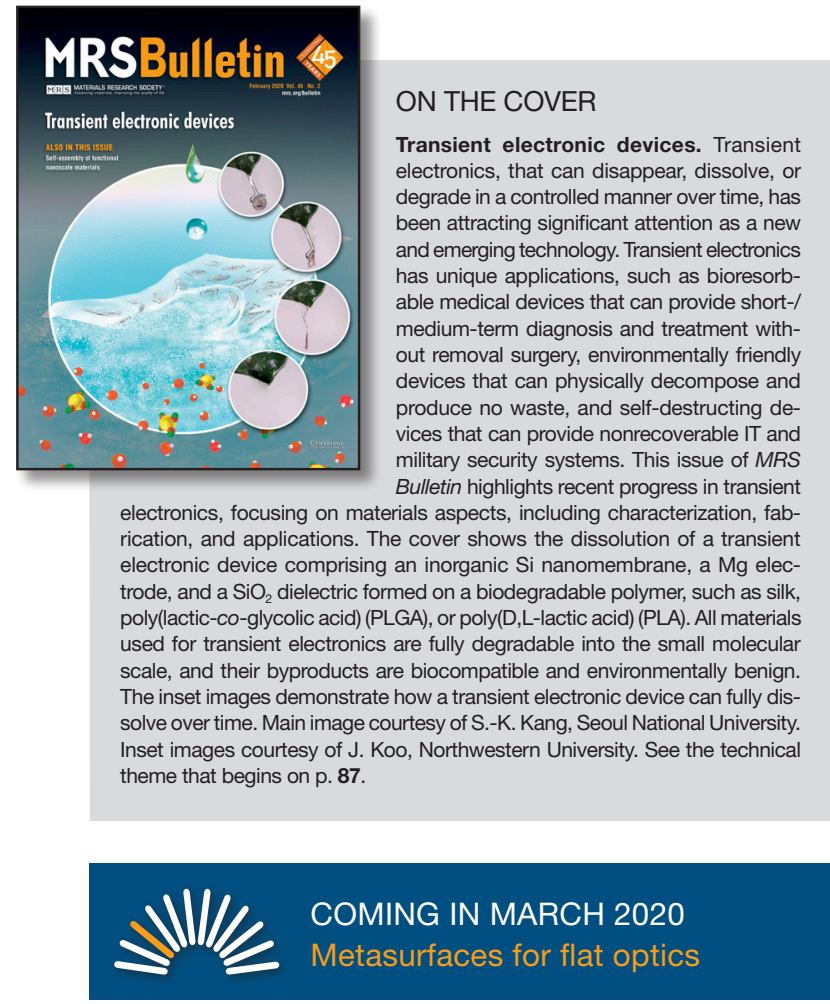


\section{DEPARTMENTS}

\section{OPINION}

77 Material Matters

US role in nuclear nonproliferation

Dylan Rittman

\section{NEWS \& ANALYSIS}

78 Materials News

- Oxide glass exhibits plasticity without fracture at room temperature

Kendra Redmond

- X-ray polarization reveals the secret to enamel's toughness

Matthew Diasio

- 2D carbon-network nanomaterial shows promise as an antibacterial agent

Stephen Riffle

82 Science Policy

- PCAST reincarnation brings promise for US materials science community

Clinton Parks

84 Public Affairs Forum

- BREWing better broader impacts

Anne Lynn Gillian-Daniel, Matthew D. Stilwell, Nicholas L. Abbott, and Wendy C. Crone

\section{SOCIETY NEWS}

142 MRS Journal Highlights

1432019 MRS Fall Meeting featured a variety of outreach, career, and professional development offerings

146 Exploring user facilities Lori A. Wilson

148 MRS Bulletin Volume Organizers guide technical theme topics for 2021

149 MRS invites nominations for awards program

\section{FEATURES}

\author{
152 Image Gallery \\ Look Again
}

\section{CAREER CENTRAL}

\section{ADVERTISERS IN THIS ISSUE}

American Elements

High Voltage Engineering

Rigaku Corporation
Page No.

Outside back cover Inside front cover 


\section{$\mathrm{M}|\mathrm{R}| \mathrm{S}$}

MATERIALS RESEARCH SOCIETY ${ }^{\oplus}$

Advancing materials. Improving the quality of life.
EDITORIAL OFFICE 506 Keystone Drive, Warrendale, PA 15086-7573 USA Bulletin@mrs.org tel 724.779.2747 fax 724.779.8313 mrs.org

\section{About the Materials Research Society}

The Materials Research Society (MRS), a not-for-profit scientific association founded in 1973 and headquartered in Warrendale, Pennsylvania, USA, promotes interdisciplinary materials research. Today, MRS is a growing, vibrant, member-driven organization of over 16,000 materials researchers spanning over 80 countries, from academia, industry, and government, and a recognized leader in the advancement of interdisciplinary materials research.

The Society's interdisciplinary approach differs from that of single-discipline professional societies because it promotes information exchange across many scientific and technical fields touching materials development. MRS conducts three major international annual meetings and also sponsors numerous single-topic scientific meetings. The Society recognizes professional and technical excellence and fosters technical interaction through University Chapters. In the international arena, MRS implements bilateral projects with partner organizations to benefit the worldwide materials community. The Materials Research Society Foundation helps the Society advance its mission by supporting various projects and initiatives.

2020 MRS BOARD OF DIRECTORS

President Matt Copel, IBM T.J. Watson Research Center, USA

Immediate Past President Michael R. Fitzsimmons, Oak Ridge Nationa

Laboratory and The University of Tennessee, USA

Vice President (President-Elect) Cherie R. Kagan, University of Pennsylvania, USA

Secretary Dawnielle Farrar-Gaines, Johns Hopkins University, USA

Treasurer Shenda Baker, Synedgen Inc., USA

Executive Director Todd M. Osman, Materials Research Society, USA

Griselda Bonilla, IBM T.J. Watson Research Center, USA

Leonard J. Brillson, The Ohio State University, USA

Kristen H. Brosnan, GE Global Research, USA

Kristen H. Brosnan, GE Global Research, USA
Coray M. Colina, University of Florida, USA

Catherine Dubourdieu, Helmholtz-Zentrum Berlin/Freie Universität Berlin, Germany Sarah Heilshorn, Stanford University, USA

Frances A. Houle, Lawrence Berkeley National Laboratory, USA

Mônica Jung de Andrade, The University of Texas at Dallas, USA

Sergei V. Kalinin, Oak Ridge National Laboratory, USA

Kisuk Kang, Seoul National University, Republic of Korea

Paul C. McIntyre, Stanford University, USA

Linda S. Schadler, The University of Vermont, USA

Christopher A. Schuh, Massachusetts Institute of Technology, USA

Rachel A. Segalman, University of California, Santa Barbara, USA

Ting Xu, University of California, Berkeley, USA

Yusheng Zhao, Southern University of Science and Technology, China

Ehrenfried Zschech, Fraunhofer Institute for Ceramic Technologies and Systems, Germany

\section{MRS OPERATING COMMITTEE CHAIRS}

Academic Affairs Sanjay Mathur, University of Cologne, Germany

Awards (Co-chairs) Suveen N. Mathaudhu, University of California, Riverside, USA

Judith L. Driscoll, University of Cambridge, UK

Government Affairs David P. Norton, University of Florida, USA

Meetings Lincoln J. Lauhon, Northwestern University, USA

Public Outreach Elizabeth Kupp, The Pennsylvania State University, USA

Publications Shefford P. Baker, Cornell University, USA

\section{MRS HEADQUARTERS}

Todd M. Osman, Executive Director

J. Ardie Dillen, Director of Finance and Administration

Damon Dozier, Director of Government Affairs

Michele L. Feder, Associate Director of Engagement

Patricia Hastings, Director of Meetings Activities

Eileen M. Kiley, Director of Communications
Editor

Gopal R. Rao, rao@mrs.org

Impact Editor

Markus J. Buehle

Managing Editor

Lori A. Wilson, Iwilson@mrs.org

News Editor

Judy Meiksin, meiksin@mrs.org

Technical Editor

Lisa C. Oldham, oldham@mrs.org

Editorial Assistants

Suzanne Hite, hite@mrs.org,

Mary Wilmoth

Associate Technical Editor

Tim Palucka

Director of Communications

Eileen M. Kiley

\section{Guest Editors}

Seung-Kyun Kang, Lan Yin, and Christopher J. Bettinger

Special Consultant

Angelika Veziridis

Production/Design

Stephanie Gabborin, Heather Shick,

Felicia Turano, and TNQ

Production Editor

Rachel Altizio

Advertising/Sponsorship

Mary E. Kaufold, kaufold@mrs.org

Donna L. Watterson, watterson@mrs.org

Member Subscriptions

Michelle Judt, judt@mrs.org

Non-Member Subscription

subscriptions_newyork@cambridge.org

\section{EDITORIAL BOARD}

Amit Misra (Chair), University of Michigan, USA

Ilke Arslan, Argonne National Laboratory, USA

N. (Balu) Balasubramanian, Bangalore, India (retired)

Christopher J. Bettinger, Carnegie Mellon University, USA

Tommie Kelley, 3M, USA

Igor Lubomirsky, Weizmann Institute, Israel

Fiona C. Meldrum, University of Leeds, UK

Steven C. Moss, The Aerospace Corporation, USA (retired)

Linda J. Olafsen, Baylor University, USA

Boaz Pokroy, Technion-Israel Institute of Technology, Israe

Zhiwei Shan, Xi'an Jiaotong University and Hysitron, China

Subhash L. Shinde, University of Notre Dame, USA

Eric Werwa, Washington, DC, USA

M. Stanley Whittingham, Binghamton University, The State University of New York, USA

IMPACT EDITORIAL BOARD

Katia Bertoldi, Harvard University, USA

Huiling Duan, Peking University, China

Peter Fratzl, Max Planck Institute of Colloids and Interfaces, Germany

Pupa Gilbert, University of Wisconsin-Madison/Berkeley National Laboratory, USA

Ali Khademhosseini, University of California, Los Angeles, USA

John A. Rogers, Northwestern University, USA

Francesco Stellacci, École Polytechnique Fédérale de Lausanne, Switzerland

Kathryn E. Uhrich, University of California, Riverside, USA

\section{ADVISORY BOARD}

V.S. Arunachalam, Center for Study of Science, Technology and Policy, India

Yuri Gogotsi, Drexel University, USA

Robert S. Langer, Massachusetts Institute of Technology, USA

Ke Lu, Chinese Academy of Sciences, China

Rodney S. Ruoff, Ulsan National Institute of Science and Technology, Republic of Korea

Edwin L. (Ned) Thomas, Rice University, USA

Peidong Yang, University of California, Berkeley, USA

\section{VOLUME ORGANIZERS}

2020 Hongyou Fan, Sandia National Laboratories, USA Oleg Gang, Columbia University and Brookhaven National Laboratory, USA Seokwoo Jeon, Korea Advanced Institute of Science and Technology, Republic of Korea Tae-Woo Lee, Seoul National University, Republic of Korea

2021 Babu Chalamala, Sandia National Laboratories, USA Paul Evans, University of Wisconsin-Madison, USA Takao Someya, The University of Tokyo, Japan Haiyan Wang, Purdue University, USA

MRS Bulletin (ISSN: 0883-7694, print; ISSN 1938-1425, online) is published monthly by the Materials Research Society, 506 Keystone Drive, Warrendale, PA 15086-7573. ( 2020 Materials Research Society. Permission required to reproduce content. Periodical postage paid at New York, NY, and at additional mailing offices. POSTMASTER: Send address changes to MRS Bulletin in care of the Journals Department, Cambridge University Press, 100 Brook Hill Drive, West Nyack, NY 10994-2113, USA. Printed in the U.S.A.

Membership in MRS is $\$ 135$ annually for regular members, $\$ 35$ for students, and includes an electronic subscription to MRS Bulletin. Print subscriptions are available to MRS members for an additional \$25. Individual member subscriptions are for personal use only. Nonmember subscription rates are \$618 (USD) for one calendar year (12 issues). Requests from subscribers for missing journal issues will be honored without charge only if received within six months of the issue's actual date of publication.

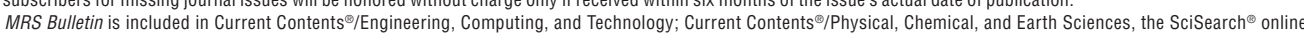
database, Research Alert ${ }^{\oplus}$, Science Citation Index ${ }^{\oplus}$, Materials Science Citation Index ${ }^{\mathrm{TM}}$, and Scopus.

Authors of each technical article appearing in MRS Bulletin are solely responsible for all content in their article(s), including accuracy of the facts, statements, and citing resources. Facts and opinions are solely the personal statements of the respective authors and do not necessarily represent the views of the editors, the Materials Research Society, or Cambridge University Press. 